$\underline{\text { Iranian Journal of Pathology | ISSN: 2345-3656 }}$

\title{
Immunohistochemical and Electron Microscopic Study of the Inhibitory Effects of Olive Oil Polyphenol on Dexamethasone-Induced Apoptosis
}

\author{
Ali Reza Khalatbary ${ }^{1 *}$, Behrooz Mohammadnegad ${ }^{2}$, Ghazaleh Goudarzi ${ }^{2}$, Ali Fazlollahpour Balef ${ }^{3}$ \\ 1. Dept. of Anatomy, Molecular and Cell Biology Research Center, Faculty of Medicine, Mazandaran University of \\ Medical Sciences, Sari, Iran \\ 2. Dept. of Anatomy, Faculty of Medicine, Mazandaran University of Medical Sciences, Sari, Iran \\ 3. Dept. of microbiology, Islamic Azad University, Qaemshar, Iran
}

\begin{tabular}{|c|c|}
\hline KEYWORDS & ABSTRACT \\
\hline Dexamethasone & Background: There is accumulating evidence that a polyphenol present in olive \\
\hline Thymocyte & oil, oleuropein, has antioxidant, anti-inflammatory and anti-apoptotic effects. This \\
\hline Apoptosis & study aimed at determining the anti-apoptotic effect of Oleuropein (Ole) on \\
\hline & dexamethasone-induced apoptosis of mouse thymocytes. \\
\hline \multirow[t]{5}{*}{ Oleuropein } & Method: Mice were randomly divided to four groups as follow: Dexamethasone \\
\hline & (Dex)-treated group ( $20 \mathrm{mg} / \mathrm{kg}$; single dose), Ole-treated group ( $20 \mathrm{mg} / \mathrm{kg}$ per day), \\
\hline & Dex plus Ole-treated group, and vehicle group. Sections of thymus were taken 16 \\
\hline & $\begin{array}{l}\text { hours after dexamethasone injection and studied for histopathological and } \\
\text { immunohistochemistry assessment. }\end{array}$ \\
\hline & Result: Further characteristics of degeneration in thymocytes were observed in \\
\hline Article Info & $\begin{array}{l}\text { the Dex group compared with the Dex plus Ole group. Compared with the Dex } \\
\text { group }(10.94 \pm 3.35) \text {, positive staining for Bax in thymocytes decreased in Dex plus }\end{array}$ \\
\hline & $\begin{array}{l}\text { Ole group }(2.64 \pm 1.26) \text {, but remained higher than the Ole }(0.65 \pm 0.30) \text { and vehicle } \\
(0.67 \pm 0.29) \text { groups. Compared with the Dex group }(2.94 \pm 0.42) \text {, positive staining }\end{array}$ \\
\hline Received 09 Dec 2015 & for Bcl-2 in thymocytes increased in Dex plus Ole group (12.24 \pm 1.84$)$ yet was lower \\
\hline Accepted 26 Jun 2016 & than the Ole $(14.94 \pm 1.54)$ and vehicle $(18.93 \pm 3.54)$ groups. \\
\hline Published Online 27 Jan 2017; & $\begin{array}{l}\text { Conclusion: Our results suggest that dexamethasone-induced apoptosis is } \\
\text { subsided by oleuropein. }\end{array}$ \\
\hline
\end{tabular}

Corresponding Information: Dr. Ali Reza khalatbary, Dept of Anatomy, Molecular and Cell Biology Research Center, Faculty of Medicine, Mazandaran University of Medical Sciences, Sari, Iran. Tel: +989122490583 Email: khalat90@yahoo.com

Copyright $($ 2016, IRANIAN JOURNAL OF PATHOLOGY. This is an open-access article distributed under the terms of the Creative Commons Attribution-noncommercial 4.0 International License which permits copy and redistribute the material just in noncommercial usages, provided the original work is properly cited.

\section{Introduction}

Apoptosis is a Programmed Cell Death (PCD), which arises from a series of specific biochemical events. This process is a fundamental physiological phenomenon, which is involved in controlling the balance between proliferation and differentiation during development, and in the optimization of cell/tissue functions throughout adulthood (1). On the other hand, inappropriate apoptosis is a factor in many human conditions including neurodegenerative diseases, ischemic damage, autoimmune disorders and many types of cancer $(2,3)$. Apoptosis can be triggered by numerous types of cellular damage and derangement, via the intrinsic apoptotic pathway (4). Meanwhile, apoptosis is an important mediator of secondary damage after traumatic injury, which is triggered by varieties of mechanisms, including free radical damage, cytokines, and inflammatory injury (5). In the recent years, much attention has been focused on apoptosis because it appears to be susceptible to therapeutic interventions with anti-apoptotic 
agents. Each treatment, which interrupts the apoptosis processes, could improve the pathological condition. In this regard, in the previous decades, a rapidly growing number of natural polyphenol compounds with anti-apoptotic effects have been described. One of the main sources of these molecules is olive oil. Olive oil is a rich source of polyphenolic components, such as its main component oleuropein $(3,4$ dihydroxyphenylel-enolic acid), which have many beneficial health effects in humans $(6,7)$. In addition, olive oil phenols have been shown to be involved in some of the protective effects against ischemia and neurodegenerative diseases such as Parkinson's (8) and Alzheimer's (9) disease. There is accumulating evidence that have attributed the beneficial effects of oleuropein and its derivatives to a variety of biological activities, including free radical scavenging/antioxidant actions, anti-inflammatory effects, and anticarcinogenic properties $(10,11)$. On the other hand, some experimental studies have documented that oleuropein and its derivatives have anti-apoptotic effects against intestinal ischemia/reperfusion injury (12), 6hydroxydopamine-induced PC12 cell apoptosis (13), and doxorubicin-induced cardiomyopathy (14). Recently, we documented that oleuropein have protective effects against acute deltamethrininduced neurotoxicity, which was partly due to alternation of apoptosis regulating proteins (15). In the present study, we exclusively investigated the potential anti-apoptotic effect of oleuropein in dexamethasone-induced thymocyte apoptosis, as a standard model of apoptosis induction, with immunohistochemical and electron microscopic assessment.

\section{Materials and Methods}

\section{Animals}

Four-week-old Balb/c mice (10-12g) were used (laboratory animal research center, Sari, Iran) in this study. They were kept under standard conditions and were fed a standard mice chow and drinking water ad libitum throughout the study period.

\section{Experimental groups}

The mice were randomly allocated to four groups, each with 5 mice: (i) Dexamethasonetreated group (Dex), which received a $20-\mathrm{mg} / \mathrm{kg}$ single dose of dexamethasone (Sigma)(16); (ii) Oleuropein-treated group (Ole), which received $20-\mathrm{mg} / \mathrm{kg}$ of oleuropein (Sigma) for 7 days (14); (iii) Dex plus Ole-treated group, which received $20-\mathrm{mg} / \mathrm{kg}$ of oleuropein for 7 days and then a 20$\mathrm{mg} / \mathrm{kg}$ single dose of dexamethasone on the seventh day; (iv) Vehicle group, which received saline.

\section{Histological assessment}

Sixteen hours after dexamethasone injection (17), the entire thymus was removed under ether anesthesia through a longitudinal midline incision and median split of sternum from the manubrium to the level of $2^{\text {nd }}$ intercostal space. Fivemicrometer serial transverse sections were prepared from the paraffin-embedded blocks with the use of a microtome. For histopathological assessment, 10 sections of each block were randomly selected, deparaffinized with xylene, stained with Hematoxylin Eosin (H\&E), and studied using light microscopy (DME; Leica Microsystems Inc., Buffalo, NY, USA). An average of 5 fields in each tissue section was evaluated. All the histological studies were performed in a blinded fashion.

\section{Immunohistochemistry assessment}

For immunohistochemistry, sections were incubated in goat serum (in order to block nonspecific site), and anti-Bax rabbit polyclonal antibody (1:50 in PBS, vol. /vol., Abcam), or antiBcl-2 rabbit polyclonal antibody (1:100 in PBS, vol. /vol., Abcam) overnight at $4^{\circ} \mathrm{C}$. Sections were washed with PBS and then incubated with secondary antibody conjugated with horseradish peroxidase (goat anti-rabbit IgG peroxidase, Abcam) for 2 hours and visualized with diaminobenzidine tetrahydrochloride for 5 minutes. Afterwards, they were dehydrated and mounted. For negative controls, primary antibodies were omitted. For quantitative analysis, immunohistochemical photographs $(n=5$ photos from each sample collected from all mice in each 
experimental group) were assessed by densitometry using MacBiophotonics Image $\mathbf{J}$ 1.41a software on an ASUS personal computer.

\section{Electron microscopic assessment}

Transmission Electron Microscopic (TEM) analysis has been considered the 'golden standard' in cell death research. In brief, for transmission electron microscopy study, small sections (approximately $1 \mathrm{~mm}^{3}$ ) of freshly excised thymus tissues were fixed in $2.5 \%$ glutaraldehyde, followed by $1 \%$ osmium tetroxide and then embedded in epon araldite. The 50-nm slices were analyzed and photographed with a Zeiss electron microscope after staining with uranyl acetate and lead citrate.

\section{Statistical analysis}

Statistical analysis was carried out using the SPSS software (Version 15, Chicago, IL, USA). Results were presented as mean values $( \pm \mathrm{SDM})$. The K-S test was used in order to evaluate the normality of the data. Also, the Tukey's multiple comparison tests and the analysis of the variance were used in order to compare each of the two groups and compare the data among the groups, respectively. A value of $p<0.05$ was considered significant.

\section{Results}

\section{Histological changes of thymocytes}

To observe the morphological characteristics of thymocytes in thymus of all experimental groups, hematoxylin-eosin staining was used in the present study. Histopathological study with hematoxylin-eosin staining has shown some degenerative changes in the vast majority of cortical thymocytes (shrinkage of individual thymocytes and condensation of nuclear chromatin) (Fig. 1A) in the thymus of Dex- treated mice. However, little signs of the degeneration were seen in Dex plus Ole-treated group (Fig. 1B) and in the Ole treated group or in the vehicle group.
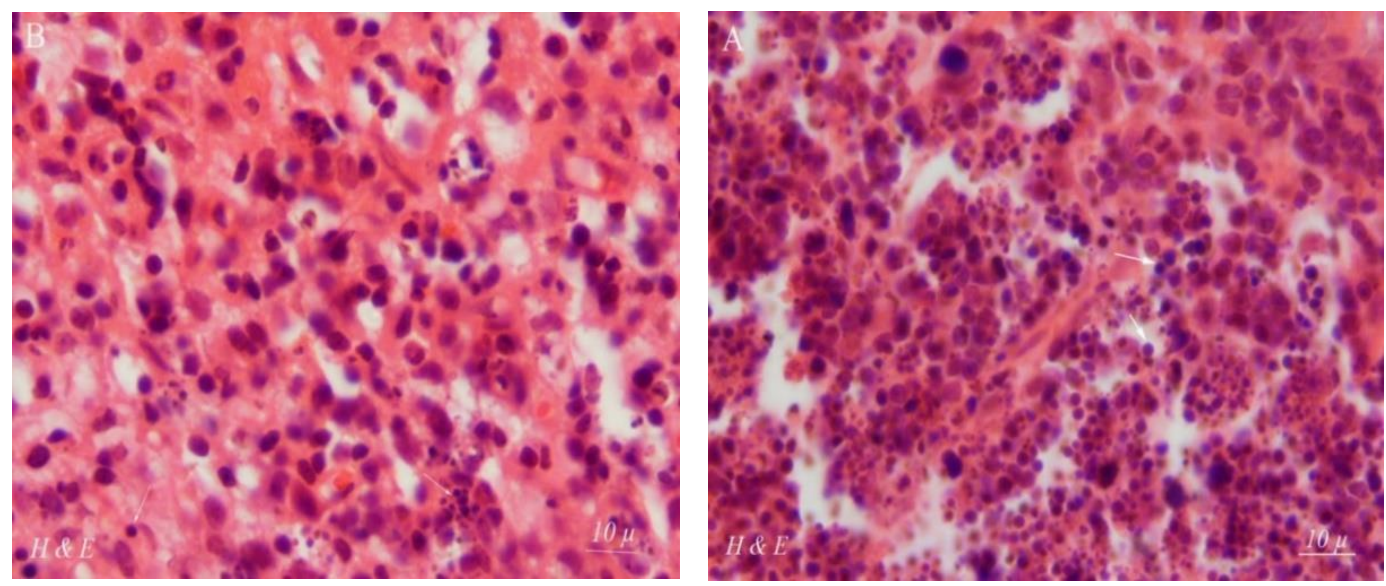

Fig 1. Hematoxylin Eosin Staining of Paraffin Sections from the Thymus of Dex (A) and Dex+Ole (B) treated-mice Many thymocytes showed characteristics of apoptosis with pyknosis of nuclei and shrinkage of cytoplasm in Dex group (arrow), 1000x. Little signs of degeneration were seen in Dex + Ole group (arrow), 1000×.

\section{Ultrastructural changes of thymocytes}

Figure 2 is a transmission electron micrograph of the thymus tissue. Figure $2 \mathrm{~A}$ shows some normal thymocytes, which is closely packed, has large nuclei and scant cytoplasm. Figure 2B is an apoptotic thymocytes in an early phase of apoptosis with condensed and peripheralized chromatin. The cytoplasm is beginning to condense and the cell outlines are irregular. It was observed that a lot of the thymocytes of Dex group displayed specific morphological changes, including reduction of cell volume, condensation of chromatin, and flocculation of the cytoplasm. However, little signs of apoptosis were seen in the Dex plus Ole group. These morphological modifications were not observed in Ole and vehicle group. 

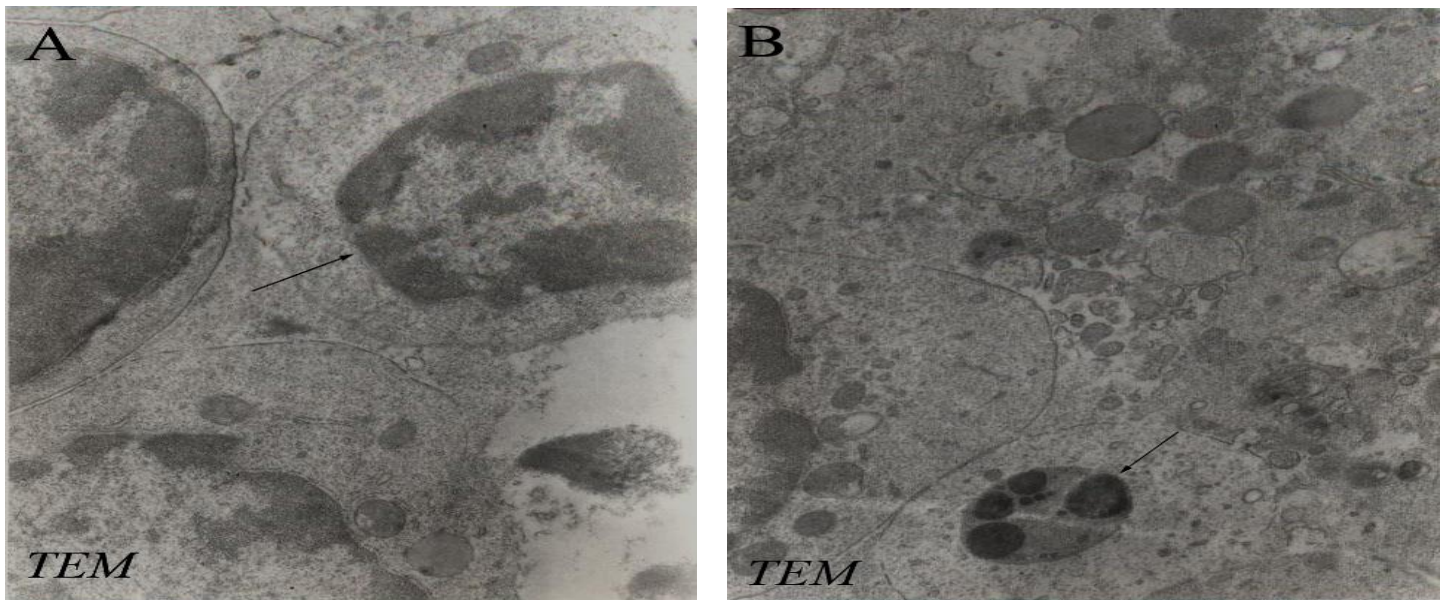

Fig 2. Transmission Electron Micrographs from the Thymus of Dex+Ole (A) and Dex (B) TreatedMice. Figure A shows some normal thymocytes with large nuclei and scant cytoplasm (arrow), $3000 \times$. Figure B shows a thymocyte with characteristics of apoptosis (condensed and peripheralized chromatin) (arrow), 3000×.

\section{Immunostaining changes for Bax and Bcl-2 of thymocytes}

Figure 3 shows the immunohistochemical staining of Bax. Thymocytes from Dex treatedmice exhibited strong positive staining for Bax
(10.94 \pm 3.35$)$ (Fig. 3A); whereas, oleuropein treatment in Dex plus Ole treated-mice reduced the degree of positive staining for Bax (2.64 \pm 1.26$)$ (Fig. 3B). Sections of Ole $(0.65 \pm 0.30)$ and vehicle $(0.67 \pm 0.29)$ treatedmice showed weak positive immunoreactions for Bax..
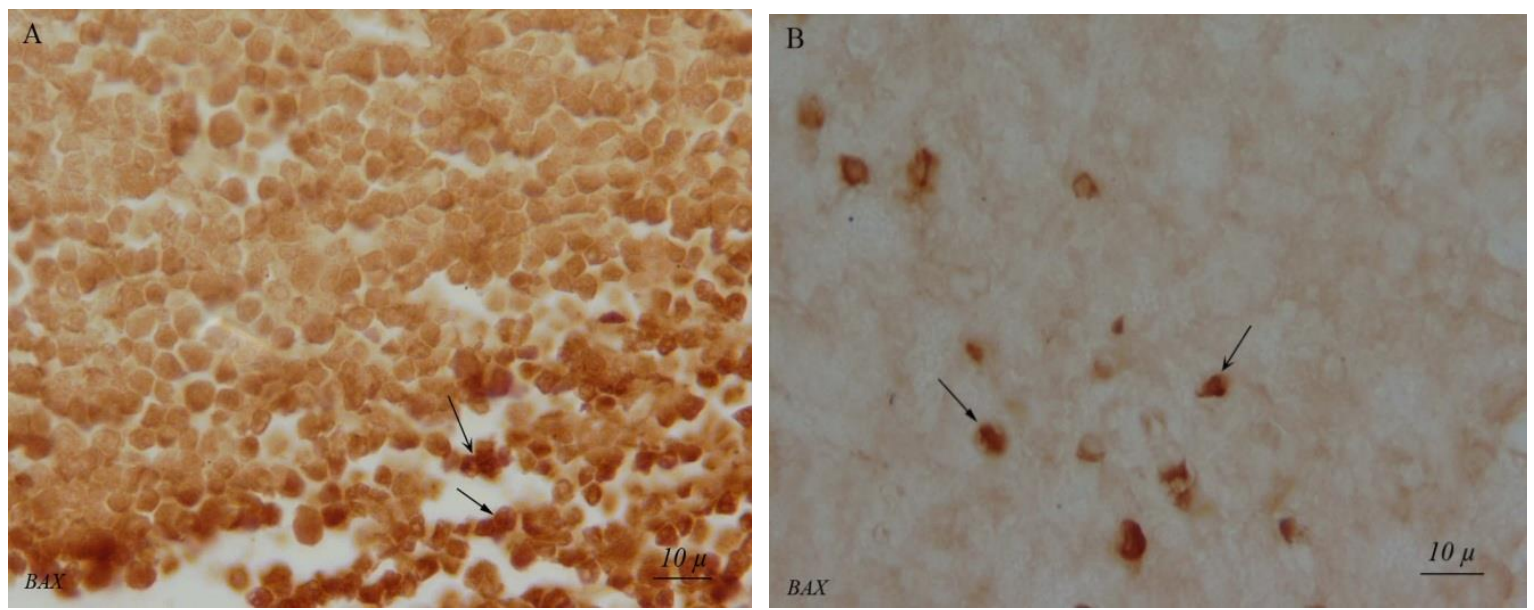

Fig 3. Light Photomicrographs Show Immunohistochemical Expression of Bax in Dex (A) and Dex+Ole (B) groups (arrow), 1000x the positive staining of Bax is presented by a brown color of cytoplasm. 


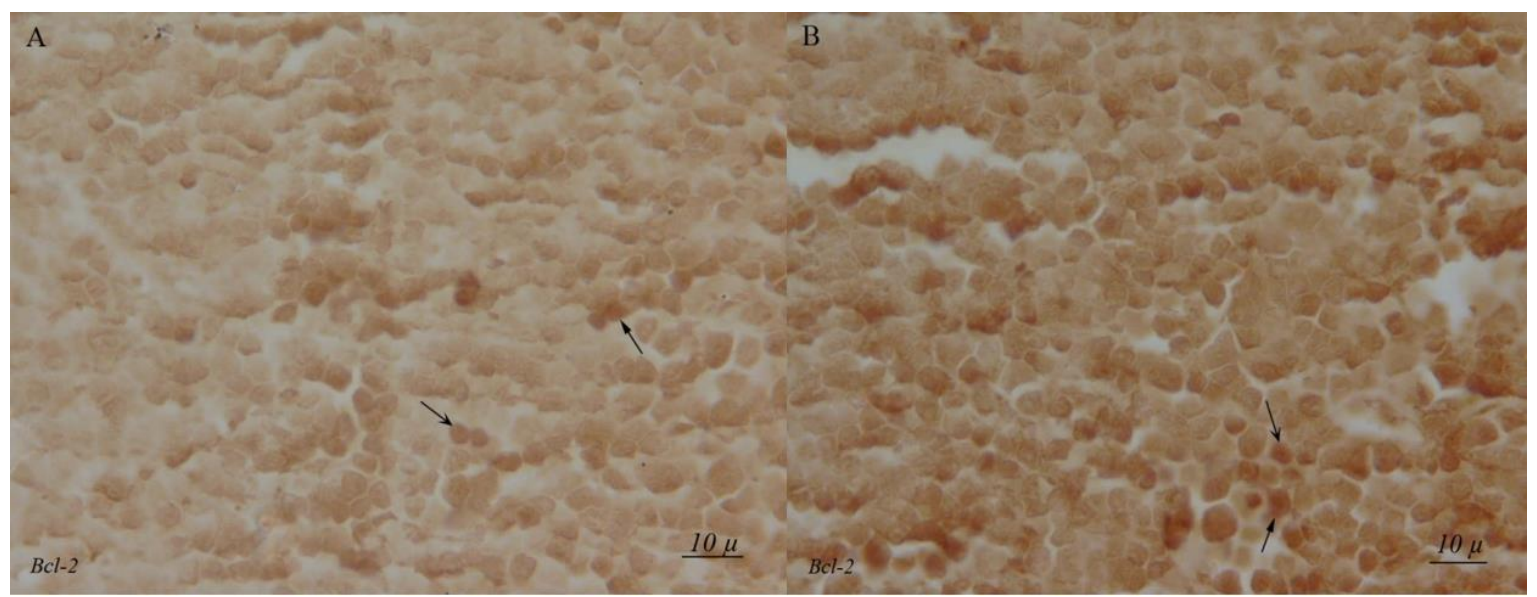

Fig 4. Light Photomicrographs Show Immunohistochemical Expression of Bcl-2 in Dex (A) and Dex+Ole (B) groups (arrow), 1000× The positive staining of Bcl-2 is presented by the brown color of the cytoplasm.

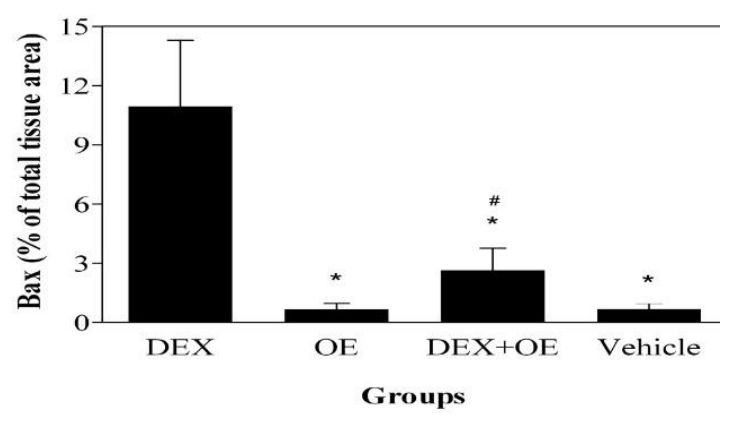

Fig 5. Densitometry Analysis of Immunohistochemical Photomicrographs for Bax

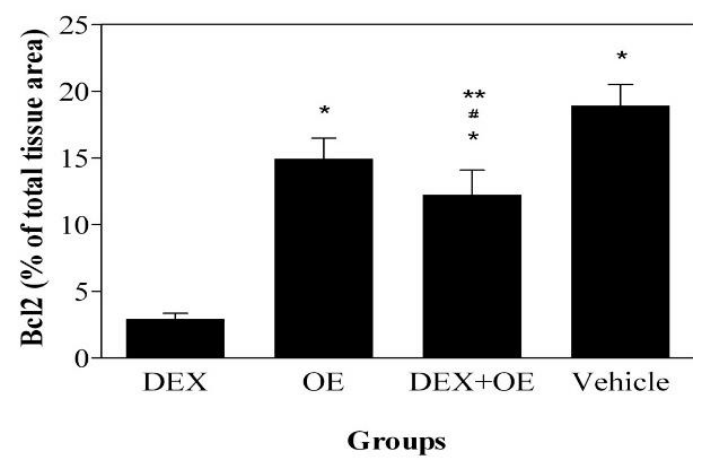

Fig 6. Densitometry Analysis of Immunohistochemical Photomicrographs for Bcl2

Data are expressed as a percentage of total tissue area. ${ }^{*} \mathrm{P}<0.001$ versus Dex group; ${ }^{\#} \mathrm{P}>0.05$ versus Ole group; $* * \mathrm{P}<0.01$ versus Vehicle group. Bars indicate the standard deviations of the mean (SDM).

Figure 4 shows the immunohistochemical staining of Bcl-2. The expression of Bcl-2 was strong in thymocytes from Ole $(14.94 \pm 1.54)$ and vehicle $(18.93 \pm 3.54)$ treated-mice, while, it was weak in the Dex treated-mice (2.94 \pm 0.42$)$ (Fig. 4A) compared to the up-regulation in the Dex plus Ole treated-mice (12.24 \pm 1.84$)$ (Fig. 4B).

\section{Quantitative analysis}

The histograms of the quantitative analysis of Bax and Bcl-2 staining in the experimental groups are shown in Figures 5 and 6, respectively.

\section{Discussion}

Apoptosis is a key molecular mechanism of some degenerative diseases and toxicities, and is regulated by the Bcl-2 family proteins (2). Among these proteins, Bcl-2 and Bax play antiapoptotic and pro-apoptotic roles, respectively (18). The ratio of Bax to Bcl-2 determines the cell fate; excess Bcl-2 leads to survival of cells, while Bax induces apoptosis $(19,20)$. Results of our immunohistochemical assessment showed that treatment with dexamethasone increased positive staining for Bax, while it exhibited a decreased positive staining for $\mathrm{Bcl}-2$ in thymocytes of Dex group. These represent a potentially avoidable event by pharmacological interventions. To date, the majority of epidemiological studies involving olive oil are linked to a decreased incidence of certain types of degenerative diseases (21-23). On the other hand, animal and human studies demonstrated that olive oil phenolic compounds are highly bioavailable; the first requirement for a dietary compound to have a potential protective effect is 
that it enters the blood circulation. In this regard, a recent study showed that after a single ingestion of olive oil phenolic compounds, these were absorbed, metabolized and distributed through the blood stream to practically all parts of the body of the rat (24). In vitro studies have suggested that anti-apoptotic properties of oleuropein and its derivatives, is a pivotal potential protective mechanism against degenerative diseases (25). Results of our immunohistochemical assessment showed that treatment with oleuropein reduced positive staining for Bax; while on the contrary, it increased positive staining for Bcl-2 in the Dex plus Ole-treated group. Conversely, oleuropein inhibited the expression of proapoptotic protein Bax and induced that of the antiapoptotic protein Bcl-2, thereby provided molecular evidence for the protective activity of oleuropein against apoptosis. In this regard, González-Correa et al. documented that lactate dehydrogenase efflux, as a marker of cell death, was inhibited, in a concentration-dependent manner after 7 days of oral treatment with hydroxytyrosol, in rat brain slices subjected to hypoxia-reoxygenation (26). An in vitro study has shown that the olive oil phenolic extract and one of its constituents, gallic acid, exert anti-apoptotic effect against $\mathrm{H}_{2} \mathrm{O}_{2}$-induced apoptotic cell death in Hela cells with reduction of time-dependent caspase 9 activities (27). Also, another study documented that incubation of PC12 cells with oleuropein could decrease cell damage and reduce biochemical markers of apoptotic cell death including activated caspase 3 and DNA fragmentation in 6-hydroxydopamine-induced PC12 cell apoptosis (13). An in vivo study and molecular examinations demonstrated that oleuropein aglycone modulated an apoptosis pathway, as shown by tunnel staining, in a murine model of intestinal ischemia/reperfusion injury (12). A recent study has shown that oleuropein prevents doxorubicin-induced cardiomyopathy through modulation of kinases such as Akt (28), a serine/threonine-specific protein kinase that plays a key role in apoptosis and cell proliferation (29).
There is some evidence that production of free radicals plays a critical role in dexamethasone-induced thymocytes apoptosis so that exogenous treatment with antioxidants or metal chelators protects these cells against apoptosis $(30,31)$. Free radicals are highly reactive molecules, defined as any chemical compound that has one or more unpaired electrons, which can have damaging effects directly on the cell, particularly on DNA, proteins, and lipids (32). These molecules have been implicated as a potential contributor to the pathogenesis of degenerative diseases. On the other hand, some studies documented that dexamethasone causes a down-regulation of several antioxidant defense enzymes (33). Oleuropein is an ortho-diphenol, with two adjacent hydroxyl groups to the ring structure (34). Antioxidant properties of ortho-diphenols are related to hydrogen-donation by forming an intramolecular hydrogen bond between the free hydrogens of their hydroxyl group and their phenoxyl radicals (35). Furthermore, oleuropein prevents free radical formation through its ability to chelate metal ions such as $\mathrm{Cu}$ and $\mathrm{Fe}$, which catalyze free radical generation reactions (36). Meanwhile, total plasma antioxidant activity has also been reported to increase in humans, after the ingestion of olive oil phenolic compounds $(37,38)$.

\section{Conclusion}

In the present study, it is clear that oleuropein pre-exposure provided protection against dexamethasone-induced apoptosis approved by electron microscopic as a golden standard, and immunohistochemical criteria. In conclusion, since apoptosis is a possible mechanism involved in cell death shown in several degenerative diseases, oleuropein might be a potent therapeutic agent in some of these conditions.

\section{Acknowledgements}

This work was supported by Molecular and Cell Biology Research Center, Faculty of Medicine, Mazandaran University of Medical Sciences. 
Conflict of Interests: The authors declare that there was no conflict of interest.

\section{References}

1. Krantic S, Mechawar N, Reix S, Quirion R. Apoptosis-inducing factor: a matter of neuron life and death. Prog Neurobiol 2007; 81: 179-196.

2. Cavallucci V, D'Amelio M. Matter of life and death: the pharmacological approaches targeting apoptosis in brain diseases. Curr Pharm Des 2007; 17: 215-229.

3. Elmore S. Apoptosis: a review of programmed cell death. Toxicol Pathol 2007; 35: 495-516.

4. Deng J, Carlson N, Takeyama K, Dal Cin P, Shipp M, Letai A. BH3 profiling identifies three distinct classes of apoptotic blocks to predict response to ABT-737 and conventional chemotherapeutic agents. Cancer Cell 2007; 12: 171185.

5. Raghupathi R, Graham DI, McIntosh TK. Apoptosis after traumatic brain injury. J Neurotrauma 2000; 17: 927-38.

6. Cicerale S, Lucas L, Keast R. Biological activities of phenolic compounds present in virgin olive oil. Int J Mol Sci 2010; 11: 458-479.

7. Waterman E, Lockwood B. Active components and clinical applications of olive oil. Altern Med Rev 2010; 12: 331-342.

8. Jones A. Can a Mediterranean-Type Diet Prevent Parkinson's Disease?. Neurol Rev 2011; 19: $1-21$.

9. Monti MC, Margarucci L, Tosco A, Riccio R, Casapullo A. New insights on the interaction mechanism between tau protein and oleocanthal, an extra-virgin olive-oil bioactive component. Food Funct 201; 2: 423-428.

10. Visioli F, Galli C, Galli G, Caruso D. Biological activities and metabolic fate of olive oil phenols. Eur J Lipid Sci Technol 2002; 104: 677684.

11. Visioli F, Poli A, Galli C. Antioxidant and other biological activities of phenols from olives and olive oil. Med Res Rev 2002; 22: 65-75.
12. Campolo M, Di Paola R, Impellizzeri D, Crupi R, Morittu VM, Procopio A, Perri E, Britti D, Peli A, Esposito E, Cuzzocrea S. Effects of a polyphenol present in olive oil, oleuropein aglycone, in a murine model of intestinal ischemia/reperfusion injury. J Leukoc Biol 2013; 93: 277-287.

13. Pasban-Aliabadi H, Esmaeili-Mahani $S$, Sheibani V, Abbasnejad M, Mehdizadeh A, Yaghoobi MM. Inhibition of 6-hydroxydopamineinduced PC12 cell apoptosis by olive (Olea europaea L.) leaf extract is performed by its main component oleuropein. Rejuvenation Res 2013; 16: 134-142.

14. Andreadou I, Iliodromitis EK, Mikros E, Constantinou M, Agalias A, Magiatis P. The olive constituent oleuropein exhibits anti-ischemic, antioxidative, and hypolipidemic effects in anesthetized rabbits. J Nut 2006; 136: 2213-2219.

15. Khalatbary AR, Ghaffari E, Mohammadnegad B. Protective Role of Oleuropein against Acute Deltamethrin-Induced Neurotoxicity in Rat Brain. Iran Biomed J 2015; 19: 247-253.

16. Schwartzman RA, Cidlowski JA. Glucocorticoid-induced apoptosis of lymphoid cells. Int Arch Allergy Immunol 1994; 105: 347-354.

17. Talaber G, Kvell K, Varecza Z, Boldizsar F, Parnell SM, Jenkinson EJ, Anderson G, Berki T, Pongracz JE. Wnt-4 protects thymic epithelial cells against dexamethasone-induced senescence. Rejuvenation Res 2011; 14: 241-248.

18. Reed JC, Jurgensmeier JM, Matsuyama S. Bcl-2 family proteins and mitochondria. Biochim Biophys Acta 1998; 1366: 127-137.

19. Zha H, Aime-Sempe C, Sato T, Reed JC. Proapoptotic protein Bax heterodimerizes with Bcl-2 and homodimerizes with Bax via a novel domain (BH3) distinct from $\mathrm{BH} 1$ and $\mathrm{BH} 2 . \mathrm{J}$ Biol Chem 1996; 271: 7440-7444.

20. Oltvai ZN, Milliman CL, Korsmeyer SJ. Bcl-2 heterodimerizes in vivo with a conserved homolog, Bax, that accelerates programmed cell death. Cell 1993; 74: 609-619.

21. Scarmeas N, Stern Y, Mayeux R, Luchsinger JA. Mediterranean diet, Alzheimer 
disease, and vascular mediation. Arch Neurol 2006; 63: 1709-1717.

22. Materljan E, Materljan M, Materljan B, Vlacic' H, Baric'ev- Novakovic' Z, Sepcic' J. Multiple sclerosis and cancers in Croatia - a possible protective role of the 'Mediterranean diet'. Coll Antropol 2009; 33: 539-545.

23. Battino M, Ferreiro MS. Ageing and the Mediterranean diet: a review of the role of dietary fats. Public Health Nutr 2004; 7: 953-958.

24. Serra A, Rubió L, Borràs $X$, Macià $A$, Romero MP, Motilva MJ. Distribution of olive oil phenolic compounds in rat tissues after administration of a phenolic extract from olive cake. Mol Nutr Food Res 2012; 56: 486-496.

25. Khalatbary AR. Olive oil phenols and neuroprotection. Nutr Neurosci 2013; 16: 243-249.

26. González-Correa JA, Navas MD, LopezVillodres JA, Trujillo M, Espartero JL, De La Cruz JP. Neuroprotective effect of hydroxytyrosol and hydroxytyrosol acetate in rat brain slices subjected to hypoxia-reoxygenation. Neurosci Lett 2008; 446: 143-146.

27. Erol-Dayi O, Arda N, Erdem G. Protective effects of olive oil pheolics and gallic acid on hydrogen peroxide-induced apoptosis. Eur J Nutr 2012; 51: 955-960.

28. Andreadou I, Mikros E, Ioannidis K, Sigala F, Naka K, Kostidis S, Farmakis D, Tenta R, Kavantzas N, Bibli SI, Gikas E, Skaltsounis L, Kremastinos DT, Iliodromitis EK. Oleuropein prevents doxorubicin-induced cardiomyopathy interfering with signaling molecules and cardiomyocyte metabolism. J Mol Cell Cardiol 2014; 69: 4-16.

29. Chen WS, Xu PZ, Gottlob K, Chen ML, Sokol K, Shiyanova T, Roninson I, Weng W, Suzuki R, Tobe K, Kadowaki T, Hay N. Growth retardation and increased apoptosis in mice with homozygous disruption of the Akt1 gene. Genes Dev 2001; 15: 2203-2208.

\section{How to Cite This Article:}

Khalatbary AR, Mohammadnegad B, Goudarzi G, Fazlollahpour Balef A. Immunohistochemical and Electron Microscopic Study of the Inhibitory Effects of Olive Oil Polyphenol on Dexamethasone-Induced Apoptosis. Iranian Journal of Pathology. 2017;12(1):45-52.
30. Baker AF, Briehl MM, Dorr R, Powis G. Decreased antioxidant defence and increased oxidant stress during dexamethasone-induced apoptosis: bcl2 prevents the loss of antioxidant enzyme activity. Cell Death Differ 1996; 3: 207-213.

31. Wolfe JT, Ross D, Cohen GM. A role for metals and free radicals in the induction of apoptosis in thymocytes. FEBS Lett 1994; 352: 58-62.

32. Watanabe H, Kobayashi A, Yamamoto T, Suzuki S, Hayashi H, Yamazaki N. Alterations oh human erythrocyte membrane fluidity by oxygenderived free radicals and calcium. Free Radic Biol Med 1990; 8: 507-514.

33. Tome ME, Baker AF, Powis G, Payne CM, Briehl MM. Catalase-overexpressing thymocytes are resistant to glucocorticoid-induced apoptosis and exhibit increased net tumor growth. Cancer Res 2001; 61: 2766-2773.

34. Vissers MN, Zock PL, Katan MB. Bioavailability and antioxidant effects of olive oil phenols in humans: a review. Eur J Clin Nutr 2004; 58: 955-965.

35. Visioli F, Galli C. Olive oil polyphenols and their potential effects on human health. J Agric Food Chem 1998; 46: 4292-4296.

36. Andrikopoulos NK, Kaliora AC, Assimopoulou AN, Papageorgiou VP. Inhibitory activity of minor polyphenolic and nonpolyphenolic constituents of olive oil against in vitro low-density lipoprotein oxidation. J Med Food 2002; 5: 1-7.

37. Bogani P, Galli C, Villa M, Visioli F. Postprandial anti-inflammatory and antioxidant effects of extra virgin olive oil. Atherosclerosis 2007; 190: 181-186.

38. Visioli F, Caruso D, Grande S, Bosisio R, Villa M, Galli G, Sirtori C, Galli C. Virgin olive oil study (VOLOS): vasoprotective potential of extra virgin oilve oil in mildly dyslipidemic patients. Eur J Nutr 2005; 44: 121-127. 